\title{
CARDIAC MYXOMA ORIGINATING FROM THE ANTERIOR MITRAL VALVE LEAFLET
}

\author{
JUNG-HAN YOON, MD'1, JI-HYUN KIM, MD'1, YOUNG-JUN SUNG, MD¹, MIN-HO LEE, MD', \\ MYUNG-JIN CHA, MD ${ }^{1}$, DO-YOON KANG, MD ${ }^{1}$, YONG-JIN KIM, MD, PHD ${ }^{1}$ AND HYUK AHN, MD, PHD ${ }^{2}$ \\ 'DEPARTMENT OF INTERNAL MEDICINE, SEOUL NATIONAL UNIVERSITY COLLEGE OF MEDICINE AND THE CARDIOVASCULAR CENTER, \\ SEOUL NATIONAL UNIVERSITY HOSPITAL, SEOUL, KOREA \\ ${ }^{2}$ DEPARTMENT OF THORACIC AND CARDIOVASCULAR SURGERY, SEOUL NATIONAL UNIVERSITY HOSPITAL, SEOUL, KOREA
}

Primary cardiac tumors are rare and myxoma is the most common tumor among them. Cardiac myxoma usually occurs in the left atrium. Myxoma originating from mitral valve is extremely rare. We report a case of mitral valve myxoma. The tumor originated from the anterior mitral valve leaflet. The tumor was completely removed and replacement of the mitral valve was not done.

KEY WORDS: Myxoma · Mitral valve $\cdot$ Heart neoplasms.

\section{INTRODUCTION}

Primary tumors of the heart are rare, and among them, myxoma is the most frequent primary cardiac tumor. ${ }^{1)} \mathrm{Al}-$ though cardiac myxoma can occur anywhere in the heart, $75 \%$ of the myxomas originate in the left atrium, generally in the area of the fossa ovalis. ${ }^{2)}$ Myxoma originating from the mitral valve is extremely rare. Here, we present a case of mitral valve myxoma.

\section{CASE}

A 62-year-old male patient was admitted to our hospital with the chief complaint of motor aphagia that developed 2 hours previous to his visit. He had a history of traumatic subdural hemorrhage, which occurred 3 years ago, but had no neurological sequelae. There was no history of fever, syncope, orthopnea, or weight loss. His physical examination was unremarkable and electrocardiography showed a normal sinus rhythm. His chest X-ray revealed no abnormal findings. Routine laboratory tests showed normal findings except for an elevated C-reactive protein (CRP) level of $0.92 \mathrm{mg} / \mathrm{dL}$ and an elevated erythrocyte sedimentation rate (ESR) of $36 \mathrm{~mm} / \mathrm{hr}$. Upon the magnetic resonance imaging of the brain, there was evidence of an acute embolic infarction (Fig. 1). As part of the patient's workup to find the source of the embolism, transthoracic echocardiography (TTE) was done. TTE revealed a highly mobile mass at the anterior mitral valve leaflet and trivial mitral regurgitation (Fig. 2A and B). The patient subsequently underwent transesophageal echocardiography, which also revealed a $1 \mathrm{~cm}$ sized mass (Fig. 2C and D). There was no thrombus in the left atrial appendage. A spherical mass was attached to the mitral valve by a short stalk and was located on the left ventricular (LV) side of the mitral valve. The mass was heterogenous in appearance, which showed central echolucent area, and prolapse of the mass into the $\mathrm{LV}$ was observed during diastole. To exclude the diagnosis of infective endocarditis, 3 pairs of blood cultures were obtained from 3 separate sites which yielded no bacterial growth after five days. The pa-
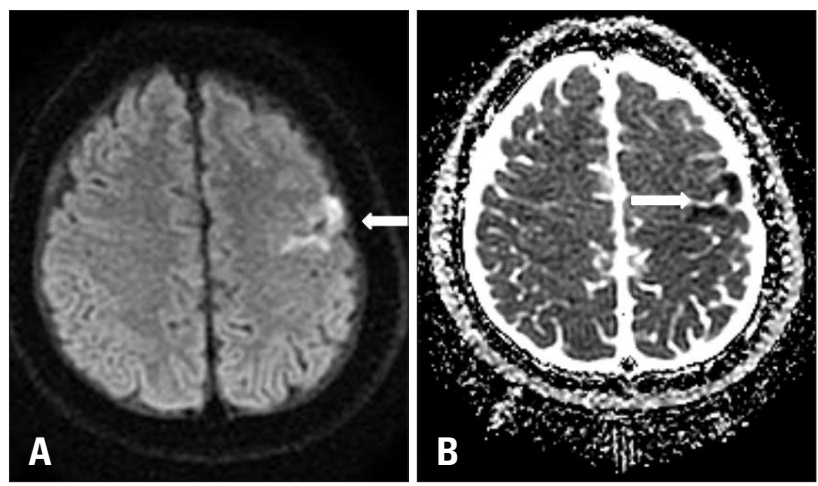

Fig. 1. Brain magnetic resonance imaging. High signal intensity lesion on diffusion weighted imaging $(A)$ with decreased signal intensity on apparent diffusion coefficient value at left precentral gyrus $(B)$ was observed which indicates hyperacute infarction.

- Received: September 27, 2011 •Revised: November 5, 2011 •Accepted: November 30, 2011

- Address for Correspondence: Hyuk Ahn, Department of Thoracic and Cardiovascular Surgery, Seoul National University Hospital, 101 Daehak-ro, Jongno-gu, Seoul 110-744, Korea Tel: +82-2-2072-3349, Fax: +82-2-762-3566, E-mail: ahnhyuk@snu.ac.kr

- This is an Open Access article distributed under the terms of the Creative Commons Attribution Non-Commercial License (http://creativecommons.org/licenses/by-nc/3.0) which permits unrestricted non-commercial use, distribution, and reproduction in any medium, provided the original work is properly cited. 

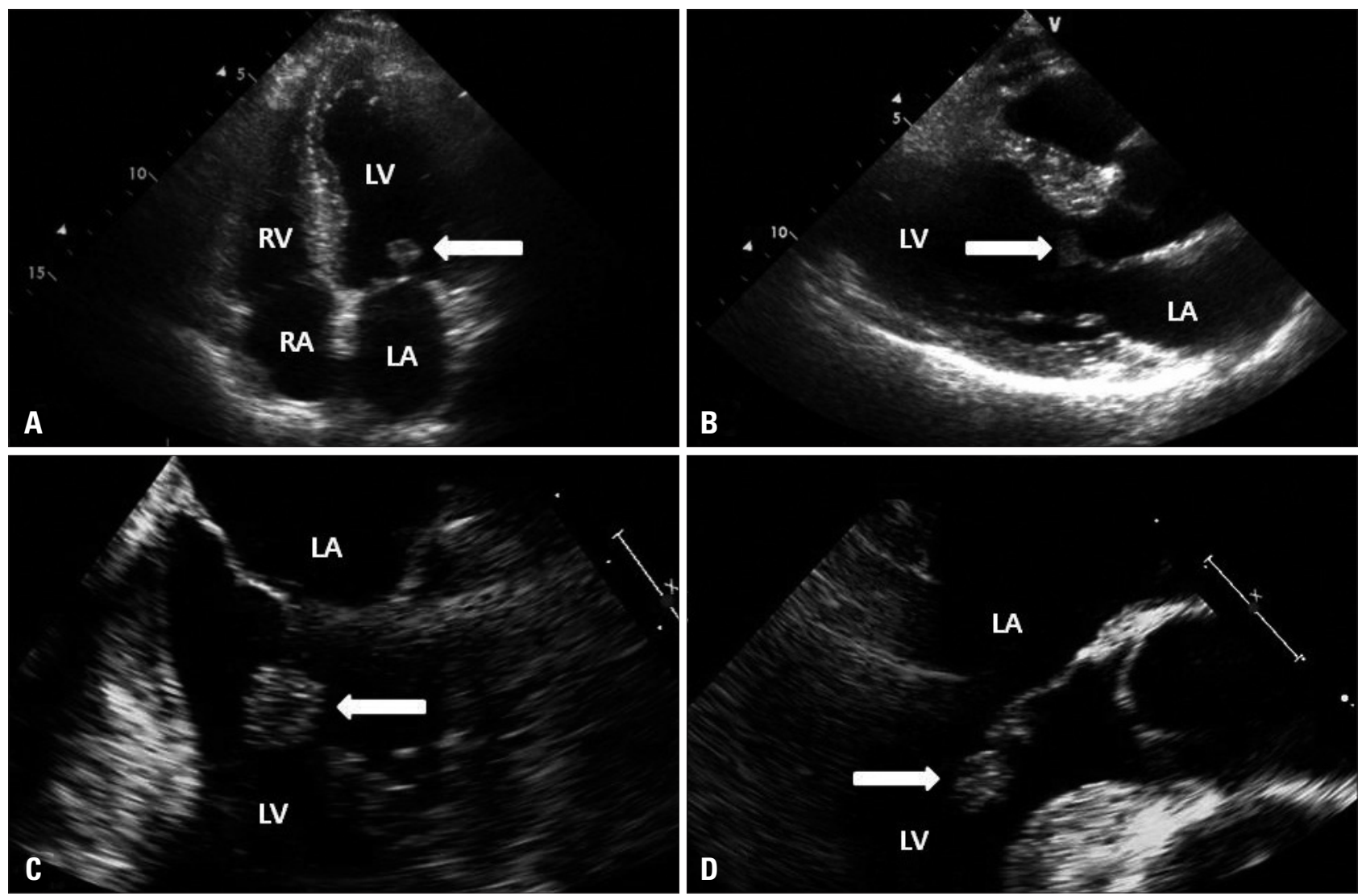

Fig. 2. The transthoracic echocardiography $(A$ and $B)$ and transesophageal echocardiography $(C$ and $D)$ showed a $1 \times 1 \mathrm{~cm}$ sized, highly mobile mass (arrows) on the anterior mitral valve leaflet. LV: left ventricle, LA: left atrium, RV: right ventricle, RA: right atrium.
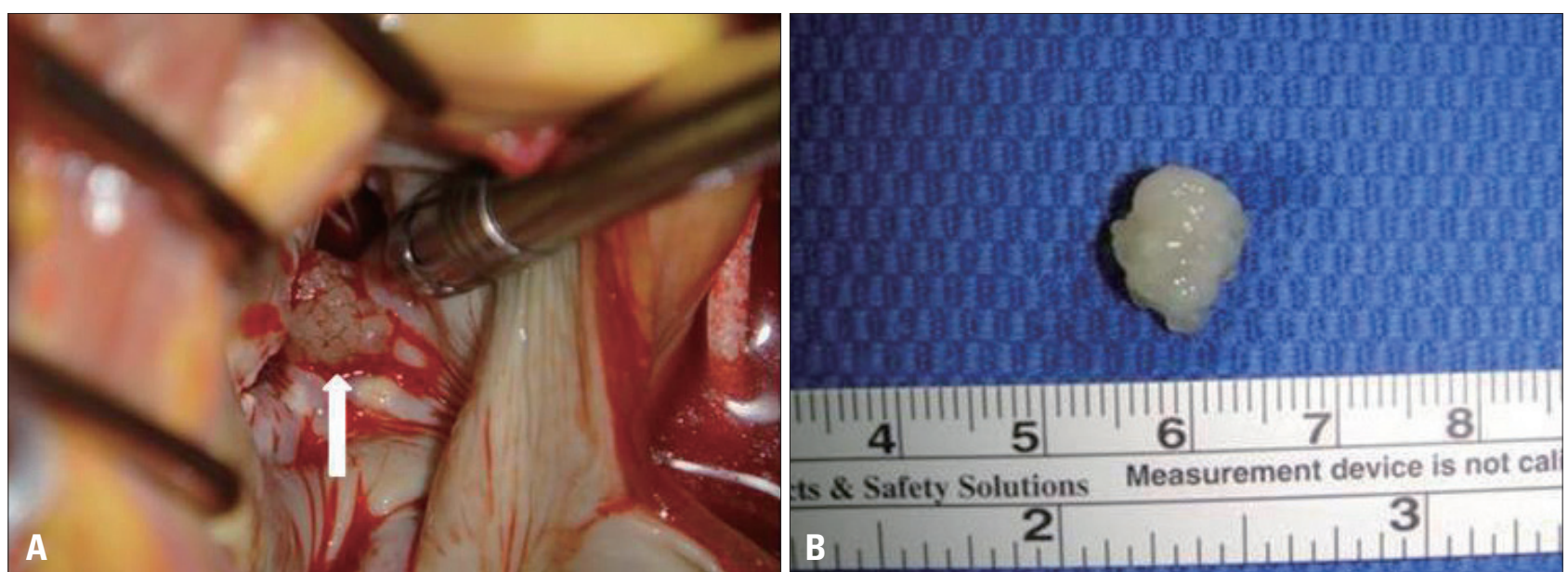

Fig. 3. Whitish, round, and soft mass (arrow) was found on the anterior mitral valve leaflet $(A)$ and it was completely excised from the mitral valve (B).

tient did not have predisposing conditions of infective endocarditis, fever, any immunologic phenomena such as Osler's node, Roth' spot, or glumerulonephritis, and other microbiologic evidence of active infection. Therefore, our case did not fulfill the Duke criteria for the clinical diagnosis of infective endocarditis. An urgent surgical resection was planned to avoid the risk of further systemic embolization.

The patient underwent sternotomy and cardiopulmonary bypass. During the operation, an $1 \times 1 \mathrm{~cm}$ sized pedunculated mass arising at the anterior mitral valve leaflet was found (Fig. 3). The mass was whitish, round, and soft, and it was attached to the mitral valve by a short narrow stalk. After complete excision of the mass, there was no sign of mitral regurgitation and replacement of the mitral valve was not done. Upon histological examination, spindle-shaped cells and stellate cells were found in a myxoid stroma, which is consistent with myxoma (Fig. 4). The patient had an uneventful postoperative course apart from an atrial fibrillation which disappeared after the use 


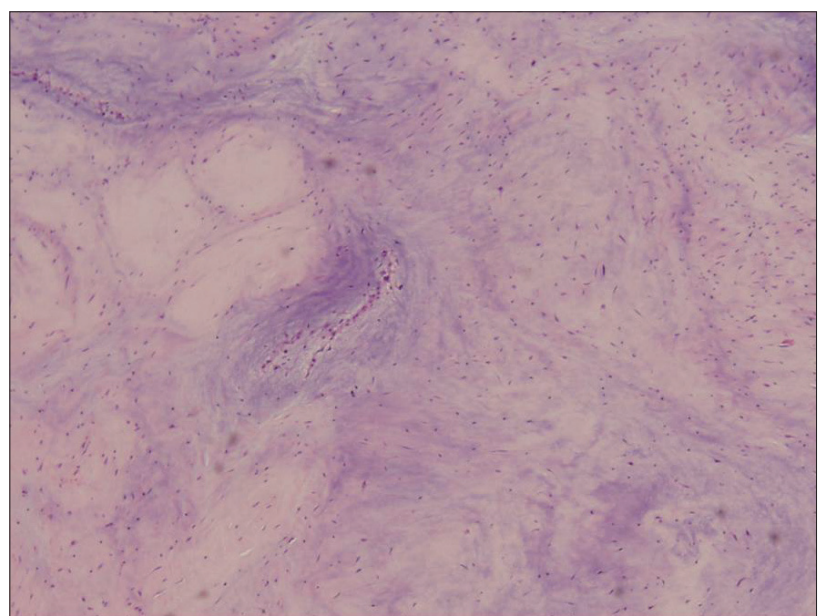

Fig. 4. Histologic examination showed spindle-shaped cells and stellate cells in a myxoid stroma (H\&E stain, $\times 100$ ).

of amiodarone. He was discharged 7 days after the operation.

\section{DISCUSSION}

Cardiac myxoma is a rare disease, with an incidence between 0.0017 and $0.03 \%$ in autopsy series. ${ }^{344)}$ Myxoma can occur in nearly all age groups but occurs frequently between the third and sixth decades of life. ${ }^{5 / 6)}$ Sixty-five percent of cardiac myxoma occurs in women." About $75 \%$ of myxomas originate from the left atrium, $18 \%$ in the right atrium, and $4 \%$ in the ventricle. ${ }^{8)}$ The exact incidence of myxomas originating from the mitral valve is not clear. In one study, it was reported as $1.5 \%$ (1 case among 68 myxoma cases). ${ }^{9}$ Myxoma originating from the heart valve was first reported by Jaleski ${ }^{10)}$ in 1934 , and the first premortem diagnosis of mitral valve myxoma was reported by Sandrasagra et al. ${ }^{11)}$ in 1979. In Korea, only 2 cases were reported since $1994 .{ }^{12113)}$ Clinical manifestations of myxoma are determined by the location, size, mobility, and friability. Clinical manifestations can be divided into three general categories: systemic symptoms, embolism, and intracardiac obstruction. Systemic symptoms such as general weakness, fever, weight loss, arthralgia, and erythematous rash have been observed, and laboratory abnormalities such as anemia, elevations in CRP, ESR, and globulin levels have also been reported in patients with myxoma. ${ }^{614115)}$ Myxoma can cause an embolism by way of the tumor emboli or thromboemboli that are released from or formed on the surface of the tumor. As most myxomas are located in the left atrium, systemic embolism frequently occurs. In most cases, the cerebral arteries are affected, and embolization into the renal, visceral, and coronary arteries has also been reported. ${ }^{8)}$ Symptoms due to intracardiac obstruction depend on the size, mobility, and location of the tumor. These symptoms include dyspnea, orthopnea, dizziness, syncope, and pulmonary edema. Whether myxoma of the mitral valve causes an embolism more frequently than a myxoma originating from the left atrium is not known.

Echocardiography is the most important and widely avail- able method in the diagnosis of myxoma. Echocardiography can provide information on the location, size, shape, and mobility of a myxoma. When abnormal mass lesions are found on the heart valve, it is important to distinguish tumorous conditions from valvular vegetations. The characteristic narrow stalk is the most important feature of cardiac myxoma, and it is helpful when diagnostic confusion exists. The location of the mass also can help to discriminate between theses 2 conditions. As vegetations typically occur on the low pressure side of a high velocity turbulence jet, vegetations are often found on the atrial aspect of the mitral valve. ${ }^{16)}$ However, there are no echocardiographic features that can absolutely differentiate myxomas from vegetations. Therefore, clinical settings must be considered when diagnosing the patient.

The treatment of choice for myxoma is surgical removal, and complete excision is the goal. Immediate postoperative mortality ranges from $0 \%$ to $3.6 \%{ }^{17118)}$ Arrhythmia is a common postoperative complication, which may require longterm medication. ${ }^{18)}$ Recurrence develops in $3 \%$ of the patients, and the rate is higher in familial cardiac myxomas. ${ }^{19)}$ It is not known whether replacement of mitral valve reduces the recurrence of mitral valve myxoma.

\section{REFERENCES}

1. McAllister HA Jr. Primary tumors of the heart and pericardium. Pathol Аппи 1979;14 Pt 2:325-55.

2. Murphy DP, Glazier DB, Krause TJ. Mitral valve myxoma. Ann Thorac Surg 1997;64:1169-70.

3. Straus R, Merliss R. Primary tumor of the heart. Arch Pathol 1945; 39:74-8.

4. Silverman NA. Primary cardiac tumors. Ann Surg 1980;191:127-38.

5. Heath D. Pathology of cardiac tumors. Am J Cardiol 1968;21:315-27.

6. Griffiths GC. A Review of primary tumors of the heart. Prog Cardiovasc Dis 1965;7:465-79.

7. Kuon E, Kreplin M, Weiss W, Dahm JB. The challenge presented by right atrial myxoma. Herz 2004;29:702-9.

8. Reynen K. Cardiac myxomas. N Engl J Med 1995;333:1610-7.

9. Wold LE, Lie JT. Cardiac myxomas: a clinicopathologic profile. Am J Pathol 1980;101:219-40.

10. Jaleski TC. Myxoma of the heart valves: report of a case. Am J Pathol 1934;10:399-406.3.

11. Sandrasagra FA, Oliver WA, English TA. Myxoma of the mitral valve. Br Heart J 1979;42:221-3.

12. Hong YS, Lee JS, Son HJ, Shin GJ, Lee WH, Kim KH. A case of myxoma of the annulus of the mitral valve. Korean J Med 1994;46:857-61.

13. Chang T, Jung JH, Park JT, Lee JE, Rim SJ, Chung N, Lim SH. A case of myxoma attached to both interatrial septum and anterior mital leaflet. Korean J Med 2004;66:630-4.

14. Peters MN, Hall RJ, Cooley DA, Leachman RD, Garcia E. The clinical syndrome of atrial myxoma. JAMA 1974;230:695-701.

15. Cohen AI, McIntosh HD, Orgain ES. The mimetic nature of left atrial myxomas. Report of a case presenting as a severe systemic illness and simulating massive mitral insufficiency at cardiac catheterization. Am J Cardiol 1963;11:802-7.

16. Otto CM. The practice of clinical echocardiography. 3rd ed. Philadelphia: Elsevier/Saunders; 2007. p.505.

17. Pinede L, Duhaut P, Loire R. Clinical presentation of left atrial cardiac myxoma. A series of 112 consecutive cases. Medicine (Baltimore) 2001;80: 
159-72.

18. Ipek G, Erentug V, Bozbuga N, Polat A, Guler M, Kirali K, Peker O, Balkanay M, Akinci E, Alp M, Yakut C. Surgical management of cardiac myxoma. J Card Surg 2005;20:300-4.
19. Bortolotti U, Maraglino G, Rubino M, Santini F, Mazzucco A, Milano A, Fasoli G, Livi U, Thiene G, Gallucci V. Surgical excision of intracardiac myxomas: a 20-year follow-up. Ann Thorac Surg 1990;49: 449-53. 